\title{
'Cure acceleration' funds woven into health reform legislation
}

When the smoke had cleared last year, it was Arlen Specter, the now Democratic senator from Pennsylvania, who had waved his legislative wand and produced more than $\$ 10$ billion in economic stimulus money for the US National Institutes of Health (NIH). Specter, a fierce advocate for medical research, has now returned for an encore, slipping a half-billion-dollar shot in the arm for translational research into the health reform bill being hammered out on Capitol Hill.

Days before the Senate approved its version of the legislation in late December, Specter inserted an amendment establishing a new $\$ 500$ million competitive grant program at the NIH, called the 'Cures Acceleration Network' (CAN). The fate of health reform was thrown into question when a Republican won a special January election for the Massachusetts Senate seat occupied by the late Edward Kennedy. Nonetheless, should ongoing negotiations harmonizing the Senate health reform bill with the House version-which does not include Specter's amendment- end successfully, signs are that Specter's brainchild will remain in the bill, not least because Democrats need his vote to ensure passage of any final version.

The network would be overseen by the NIH director, with advice from a board of 24 experts drawn from academia, venture capital firms, government agencies and disease advocacy groups. It would disburse individual grants of up to $\$ 15$ million per year to speed potential therapies from bench to bedside. Awardees with access to private funds would be required to match every three government dollars with one private dollar. Key to CAN's functioning would be early and close coordination with the Food and Drug Administration to ensure that a drug's development meets regulatory requirements.

"We must do this on the scale and with the focus of the way we sent astronauts to the moon," Specter said in a statement.

Specter's main target is the so-called 'valley of death'- the gap between the discovery of a potential drug and the point at which it is ready for commercial development. Often, promising discoveries languish because scientists and small companies lack the legal, financial and regulatory resources to push them through the valley.

Although the NIH currently supports 46 clinical and translational science awards with funding approaching $\$ 500$ million annually, the size of these grants enables institutions to develop infrastructure and do training but provides only limited funding for actual projects, says Garret FitzGerald, director of the Institute for Translational Medicine and Therapeutics at the University of Pennsylvania in Philadelphia, who is the principal investigator on one of these grants.
For this reason, CAN is "a wonderful idea, but a wonderful idea that needs new resources, not a wonderful idea that needs carving out of existing, limited NIH resources," FitzGerald says.

The Specter proposal is being hailed by disease and research advocacy groups. Specter "once again has his finger on the pulse of public sentiment," says Mary Woolley, the president of Research!America, an advocacy group based in Alexandria, Virginia. "The public wants more solutions and they want them faster. That's exactly what this CAN amendment is poised to accomplish."

But the Specter amendment does not include the extra money needed to finance CAN, relying instead on Congressional spending committees to deliver the funds during their annual budgeting process. Because of this, some scientists worry aloud that, if included in the final bill, the amendment could force the NIH to siphon finite dollars away from basic, investigator-initiated research.

Mark Lively, president of the Federation of American Societies for Experimental Biology, based in Bethesda, Maryland, says his group does not oppose Specter's initiative. But, "if there are redistributions of funds within NIH from other programs near and dear to our society's heart-that's when you'll hear from us."

Meredith Wadman, Washington, DC

\section{Gawande floats idea for health delivery institute}

The US government should create a new federal institute tasked with improving research into how health care is delivered, according to Atul Gawande. The wellknown Harvard surgeon and New Yorker staff writer floated the idea at a unique stop during his cross-country book tour, when he spoke to the President's Council of Advisors on Science and Technology (PCAST) in Washington, DC last month.

"We need basic and applied research on the health system for the discovery of practical know-how," Gawande told the PCAST members. "It is life-saving research. It is neglected work that would identify the systems innovations that could improve American health care."

Lifting a page from his most recent book, The Checklist Manifesto, Gawande called for greater research ranging from simple health solutions, including checklists for standard surgical protocols, to more complex investigations, such as how to bundle payments for all services related to a single treatment.

Gawande's preferred solution would involve establishing a National Institute of Health Systems Innovation-designed, ideally, to stand alongside the National Institutes of Health (NIH). He noted, however, that it would also be possible to shore up delivery research at the NIH or other existing agencies, such as the Centers for Disease Control and Prevention's National Center for Health Statistics or the Agency for Healthcare Research and Quality.

"We could do much more and we could do it so much better," Nancy Chockley, president of the National Institute for Health Care Management, a nonprofit group in Washington, DC that is unaffiliated with the $\mathrm{NIH}$, told Nature Medicine. Right now, no one in government is doing health systems research at a large scale, she says, "and there's an incredible need to improve our system."

Gawande's recommendations were warmly received, but some PCAST members voiced reservations about introducing new administrative bureaucracy. "I do have some concerns about the idea of creating a separate domain under which this type of research is done," said PCAST co-chair and former NIH head Harold Varmus of Memorial Sloan-Kettering Cancer Center in New York.

Regardless of what organizational solution is devised, "it is a very different way of thinking," noted Eric Lander, PCAST co-chair and director of the Broad Institute in Cambridge, Massachusetts.

Elie Dolgin, New York 